\title{
Election 2015: party platforms on health issues
}

$\mathrm{T}$ o a surprising degree, health care has gradually emerged as an issue in the 2015 federal election with party leaders touching on issues such as seniors care and pharmacare during their campaigns. But announcements were sporadic and commitments scattered, making it difficult to keep track of who said what.

In the interest of setting the record straight, CMAJ asked the leaders of the five major federal parties to respond to 10 questions about health care. These questions covered much-touted health issues such as pharmacare, as well as more rarified concerns such as climate change and implementing the recommendations of the federal Advisory Panel on Healthcare Innovation.

Regrettably, the Conservatives and Bloc Québécois declined repeated requests to answer the questions. This is rather puzzling in the case of the Bloc, whose Leader Gilles Duceppe told the Montreal Gazette on Sept. 8 that "Health care is certainly the most important issue in the federal election campaign." At the Conservative campaign headquarters, staffer Meagan Murdoch said "We do not answer surveys or questionnaires." Oddly, they did answer one for the Canadian Nurses Association.

The New Democratic Party (NDP) responded Sept. 21, and warned that their party's platform may evolve in the ensuing weeks. We asked the parties to limit their responses to 150 words; some were shortened. The responses are presented in the order we received them.

Given the tenants of the Canada Health Act, what leadership role should the federal government take in Canada?

New Democrats: Years without federal leadership has stalled pan-Canadian health human resource planning, home care standards, cooperation to reduce drug costs and other important initiatives. Provinces and territories continue, on their own, to collaborate to

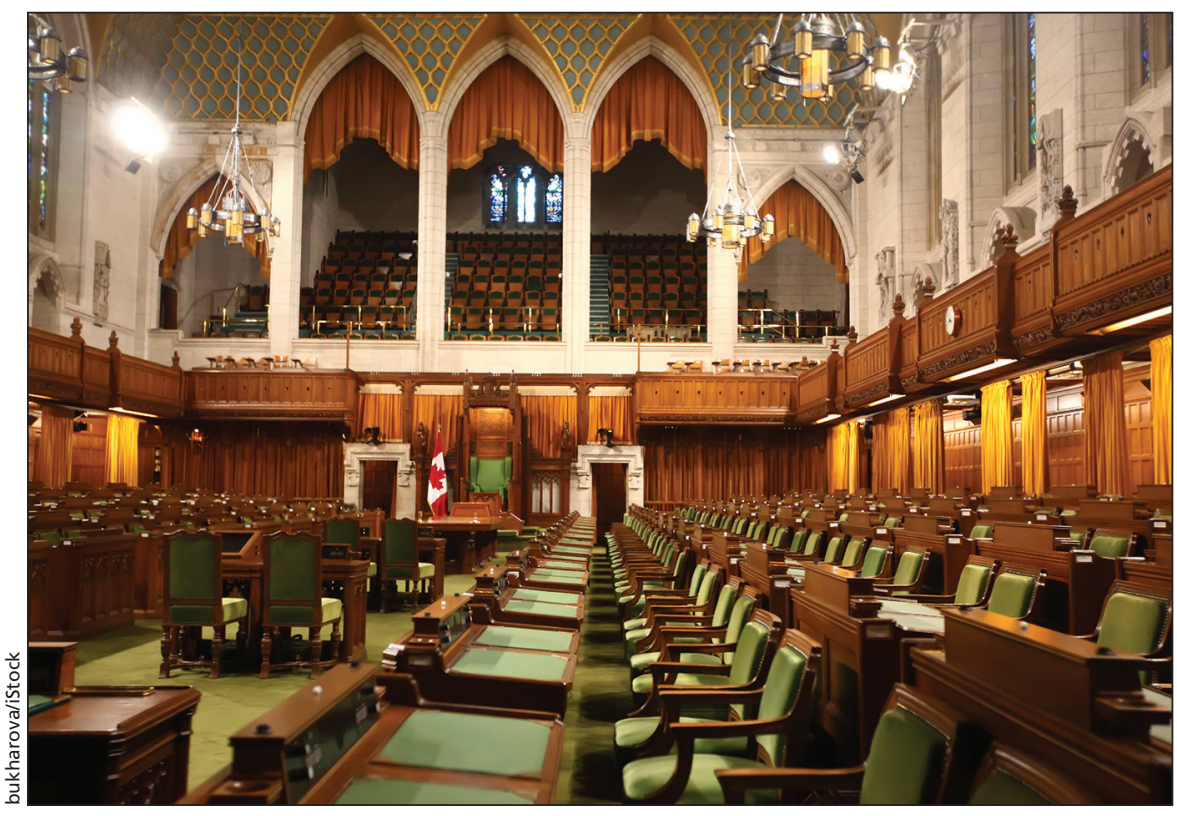

The federal government's role in health care will vary widely depending on which party dominates the House of Commons.

an extent, but the lack of federal leadership in addressing these challenges is undermining the development of effective national strategies to meet the needs of Canadians.

We are strongly committed to rejuvenating the relationship between the federal government, provinces and territories to provide Canadians with the health care they need. A NDP government will usher in a new era of collaboration. Respecting provincial roles, we will lead strategies to fill gaps and make public health care more sustainable over the long term.

We will initiate discussions with the provinces and territories on developing a new set of health care agreements. Canadians can also count on a New Democratic government to uphold the Canada Health Act to protect our public system.

Liberals: A new Liberal government will show leadership on health care. We will re-engage on Canadian health care and negotiate a new health accord with provinces and territories, including a long-term agreement on funding.
We will invest $\$ 3$ billion over the next four years to prioritize additional and improved home care services for all Canadians. We are committed to ensuring an integrated primary care system in Canada that is multidisciplinary, patient centered and committed to managing chronic disease within community, home, and long-term care settings. We will work with the provinces and territories to ensure all Canadians have access to high-quality in-home caregivers, financial supports for family care, and, when necessary, palliative care.

As part of our 10-year investment of nearly $\$ 20$ billion in social infrastructure, we will prioritize new investment in affordable housing and seniors' facilities - including long-term care facilities. We will also expand the Employment Insurance Compassionate Care Benefit.

Green: Universal health care requires strong federal leadership. The five guiding criteria of the Canadian Health Act (CHA) are nonnegotiable. The Green Party of Canada is firmly opposed to two-tier and privatized for- 
profit health care. Green MPs welcome a serious and long-overdue debate about how better to protect the core elements of single-payer health care to ensure more fairness and efficiency. Green MPs would use the full force of federal spending power under the CHA and all other available means to oppose any steps that open the way to further two-tier health care in Canada.

The Green Party is committed to providing adequate federal funding for health care. We will renegotiate the Canada Health Accord and restore federal investment to support a truly universal public health care system. Green MPs will advocate for increased funding to hire and train more doctors and nurses, purchase new diagnostic equipment, expand long-term residential and home care, and for health human resources.

Compared to Canadians overall, Aboriginal people have lower life expectancy, and higher rates of infant mortality, suicide, diabetes, mental health disorders and obesity. The Truth and Reconciliation Commission called on the federal government to close the gaps in health outcomes. What would your government do to improve the health of Aboriginal peoples?

New Democrats: A NDP government is committed to making significant progress in raising the standard of Indigenous health in Canada. A NDP government will work in partnership with First Nations, Inuit and Métis communities to start closing the gap in health outcomes.

First Nations communities are still handcuffed by the punitive $2 \%$ cap on annual funding increases for programs and services. We will eliminate this cap. Our nation-to-nation approach will enable the collaborative development of practical, community-based strategies to deal with poverty and its health consequences.

[To address] the extraordinarily disproportionate rate of suicide among Indigenous youth, [the NDP will] establish a \$100-million Mental Health Innovation Fund for Children and Youth. [We will also] fully implement
Jordan's Principle - a child-first principle that ensures that, when there is a jurisdictional dispute over which level of government should pay for an Aboriginal child's care, whichever government was first contacted will provide the service, and later seek resolution of the jurisdictional dispute.

Liberal: A Liberal government will work with indigenous peoples to build a renewed relationship based on trust, respect, and mutual understanding.

We will lift the $2 \%$ cap on funding increases for First Nations programs. That limit has not kept up with the demographic realities of Aboriginal communities or the costs of program delivery.

We will address poverty and lack of opportunity with renewed investments in First Nations education, renewed commitments to Nutrition North and other initiatives. To help Northern residents with higher costs of living, we will increase the residency component of the Northern Residents Deduction by 33\% and index it. To ensure that Northern families have access to affordable, healthy food, we will increase investments in the Nutrition North program by $\$ 40$ million over four years. The Liberal Canada Child Benefit will provide support to those who need help most and lift 315000 children out of poverty.

Green: The disparity between the health care provided to Aboriginal and nonAboriginal communities is a national disgrace. Life expectancy in Aboriginal communities is lower, disability rates are higher, infant mortality is higher, infectious diseases are more common, diabetes is more prevalent and the suicide rate is shocking. Yet we have seen no leadership, only cut after cut to Aboriginal health care programs. This is a mark of institutional racism, and a legacy of the cultural genocide described recently by the Truth and Reconciliation Commission (TRC). The Green Party has committed to fight for the implementation of the TRC recommendations, including those on health, "to recognize and implement the healthcare rights of Aboriginal people as identified in international law, constitutional law, and under the Treaties."
By 2036, people over age 65 will make up a quarter of Canada's population (up from 14\% today) and account for $62 \%$ of health costs (up from about half today). What healthrelated measures/programs would your party introduce in response to the aging population?

New Democrats: A New Democratic government will invest $\$ 1.8$ billion over four years to help provinces improve seniors care, including stronger home care, more nursing home beds and better palliative end-of-life care. This funding can expand home care services to 41000 additional seniors; help provinces build 5000 more nursing home beds; and establish a \$30-million palliative care innovation fund.

We will work closely with the provinces and territories, respecting their role in health care delivery, to [identify priorities].

A New Democratic government will also work with provinces and territories to establish a National Alzheimer's and Dementia Strategy using the principles included in Claude Gravelle's Bill C-356. [It will be guided by a new] Canadian Alzheimer's and Dementia Partnership, which will bring together provinces, researchers, the Alzheimer Society and other experts. We will dedicate $\$ 40$ million over the next four years to support the strategy and help provinces improve dementia research and care.

Liberals: Investing in home and community-based services is more cost effective and provides better outcomes for patients. To this end, we will make a \$20-billion investment in social infrastructure over the next 10 years. This will allow provinces and municipalities to construct sorely needed affordable housing for seniors, long-term care infrastructure, and seniors' facilities.

Poverty is intimately linked to health outcomes, especially among Canadian seniors. That is why we will work with the provinces to expand the Canada Pension Plan and restore the age of Old Age Security/Guaranteed Income Supplement (GIS) eligibility to 65. We will increase the GIS for single, lower-income seniors by $10 \%$, provid- 
ing up to an additional $\$ 920$ per year for Canada's lowest-income seniors.

We will also make the Compassionate Care Benefit more flexible and easier to access, so that those who are caring for seriously ill family members can access six months of benefits.

Green: As Canada's population ages, we are faced with the challenge and opportunity to provide seniors with independence and dignity in their health care. In order to address the many issues facing seniors, we are advocating for a National Seniors Strategy. Among other things, this strategy would:

- implement a Guaranteed Livable Income, which supplements pensions and will ensure no Canadian lives in poverty;

- create a National Housing Plan with affordable and predictable home care;

- support a national Aging in Place approach to ensure every Canadian can live in their own home and community safely and comfortably;

- increase the Canada Health Transfer to account for the age of a province's population, so they can afford to provide health care with a demographic that is weighted with seniors; and

- create a National Dementia Strategy, which includes more long-term care beds in neighbourhood facilities and improved supports for family members.

A recent $C M A J$ study indicates that national pharmacare could slash spending on prescription drugs by $\$ 7.3$ billion annually. What should the federal government do to control spending on pharmaceuticals while ensuring that all Canadians have access to the medications they need?

New Democrats: A New Democratic government will invest $\$ 2.6$ billion in new federal funding to initiate universal public drug coverage, to be phased in over the next four years and reaching $\$ 1.5$ billion annually in $2019 / 20$. This commitment does not depend on matching funds from the provinces and territories.
The NDP will work with provinces, pool our resources and leverage our combined strength so that together we can:

- negotiate lower drug prices that are more in line with other developed countries;

- bulk purchase prescription drugs at better prices; and

- streamline the drug review and listing process, reducing duplication and overhead costs for the provincial and federal governments.

To support this partnership, we will dedicate a further $\$ 80$ million over four years to improve provincial-federal capacity for drug reviews, listing, joint pricing negotiations and improving safety by reducing inappropriate prescribing.

New Democrats are committed to working collaboratively to finally introduce a national plan to lower Canadians' costly output on drugs within our public health system.

Liberals: A Liberal government will improve access to necessary prescription medications. We will join provincial and territorial governments to negotiate better prices for prescription medications and to buy them in bulk reducing the cost governments pay to purchase drugs. We will support and disseminate research and best practices to reduce unnecessary overprescribing of medications, particularly for the elderly, who often take multiple medications. We will prioritize decreasing the number of harmful, adverse drug reactions by improving reporting, and ensuring more research and followup on reported adverse effects. We will continue to ensure timely approvals for new medicines, many of which not only improve patient health but reduce overall health care costs as well. We will consult with industry and review the rules used by the Patented Medicine Prices Review Board to ensure value for the money governments and individual Canadians spend on brand-name drugs.

Green: Every developed country in the world with a universal health care system provides prescription drug coverage, except Canada. Truly universal health care means guaranteeing that all
Canadians have access to the medication they need. We will implement a National Pharmacare Plan that, through the advantage of bulk buying, will actually save Canadians $\$ 11$ billion each year. It will especially benefit senior citizens, who spend the most on prescription medication, and it will allow physicians and doctors to better track if patients are at risk of dangerous overmedication.

We will be far more rigorous in assessing new drug applications. We will apply the gold standard for pharmaceutical review to ensure we reject drugs shown to hurt more people than they heal. At the same time, our pharmacare plan will provide much needed coverage to the millions of Canadians who are forced to pay out-of-pocket for prescription medication every year.

Mental illness constitutes more than $15 \%$ of the disease burden in Canada, but funding for mental health care is $7 \%$ of the total expenditure on health. What would your government do to address this gap?

New Democrat: The NDP will work with the provinces and territories to improve access to mental health care services for children and youth. We will establish a \$100-million Mental Health Innovation Fund for Children and Youth to improve care for children and youth. This four-year fund will contribute:

- $\$ 15$ million annually for health care providers and community mental health associations to implement best practices that reduce wait times and provide appropriate care; and

- \$10 million annually for research and sharing information among healthcare providers across the country.

Working with the provinces, this fund will prioritize high-risk populations, including First Nations, Inuit and Métis, Canadians in rural and remote communities and youth transitioning out of foster care.

We will work also with the provinces and territories to better integrate mental health services for all Canadians into primary care, building on the community-based clinic model. 
Liberals: A Liberal government will increase the availability of mental health services for Canadians. This includes implementing an integrated approach to ensure access to acute services, tertiary care referrals, housing, primary care, and community and multidisciplinary team management. We will establish a pan-Canadian Expert Advisory Council on Mental Health to advise on the implementation of the Mental Health Commission of Canada's recommendations. We will create new centres of excellence that will specialize in mental health, post-traumatic stress disorder, and related issues for both veterans and first responders.

We are committed to supporting the mental health of veterans. In addition to restoring lifelong pensions for injured veterans, we will invest $\$ 100$ million per year to expand support for the families of veterans. This will include education, counseling and training for families who are providing care and support for veterans living with physical and/or mental health issues as a result of their service.

Green: We believe we need a comprehensive approach to mental health. We will work to extend the mandate of the Mental Health Commission of Canada (MHCC) for another ten years. We remain committed to working with the provinces, First Nations, Inuit, and Métis governments to implement a mental health strategy in line with recommendations from the Mental Health Commission of Canada.

We must increase funding transfers for noninstitutionalized mental health patients to provide community-based support, and outpatient and inpatient care by mental health practitioners, especially in rural Canada. This can only be accomplished with an adequately funded, robust, and comprehensive mental health strategy for all Canadians. With one in five Canadians experiencing mental health issues during their lifetimes, and at a cost to our economy of more than $\$ 50$ billion annually, no one is untouched by its effects. It is essential that we do more to prevent mental illness, expand access to care and work to combat the stigma of mental illness.
With the Supreme Court of Canada's unanimous decision to overturn the ban on physician-assisted death taking effect on Feb. 6, 2016, pressure is mounting for federal laws to regulate the practice. What strategy would your party take to expedite the process?

New Democrats: We recognize that there are profound and highly complex medical, ethical and legal implications involved in the care of terminally ill patients - and that physician-assisted dying engenders strong feelings, touching many Canadians in a very personal way.

If elected, A NDP government under Tom Mulcair can be trusted to make access to palliative care a priority, while taking immediate steps to implement the Supreme Court of Canada's historic and unanimous Carter decision swiftly with balance, respect and sensitivity.

Liberals: A Liberal government will immediately begin consultations for physician-assisted death, respecting the Supreme Court of Canada's ruling in the Carter v. Canada case and in accordance with the Supreme Court's deadline. We will immediately appoint a special committee to consider the ruling of the Supreme Court, consult with experts and Canadians and make recommendations for a legislative framework that respects the Constitution, the Charter of Rights and Freedoms and the priorities of Canadians.

Physician-assisted dying is a complex and emotional issue that touches the lives of a great number of Canadians. Canadians expect their elected representatives to take a leadership role on this issue. They also expect a respectful and responsible conversation about strengthening end-of-life care and support, including palliative care.

Green: The Green party will swiftly implement the unanimous Supreme Court decision respecting an adult's ability to decide their own end-of-life care when they suffer from grievous and irremediable medical conditions.

We will convene Parliament without delay and initiate broad and urgent con- sultations on the best possible framework. We are ready to immediately advocate for this legislation in a new Parliament, having already taken this compassionate position. We will, however, remain vigilant to ensure the decision to die with dignity is made by the patient in question and nobody else.

The Supreme Court gave Parliament a full year. Our inaction up to now is no excuse for missing the Court's deadline and leaving doctors and patients in limbo. In the event that other parties are not prepared to move quickly to meet the Supreme Court's Feb. 6, 2016 deadline, we will not support a request to the Supreme Court for an extension of the deadline.

The federal Advisory Panel on Healthcare Innovation recommended establishing an arms-length health care innovation fund to finance high-impact initiatives, break down structural barriers and accelerate innovation. What would your party do to spur innovation in health care?

New Democrats: Innovative change creative, inventive initiatives - is key to resolving the outstanding issues across our health care system. We believe the federal government has a pivotal role to play in bringing innovative quality health care solutions equitably and effectively to Canadians no matter where they live. This may be technological innovation - like developments in e-health - or innovations in primary care human resource allocation, pharmaceutical research and other areas.

A New Democratic government will breathe new life into federal-provincial-territorial collaboration to open the door to the sharing, implementation and promotion of innovative solutions across Canada.

As well, a NDP government is already committed to directly supporting innovation through dedicated funding, as in our \$100-million Mental Health Innovation Fund for Children and Youth.

Innovation has become the new catchword in health care. New Democrats intend to translate that word into an agenda for action to deliver the ben- 
efits of health innovation into the hands of Canadians as quickly and as effectively as possible.

Liberals: We believe in the ability of government to be a force for good in society and understand that investments in research, technology and innovation are investments in Canada's future. Liberals believe Canada can do more to help firms that are working on new ideas and technologies that can be brought to market and create good middle-class jobs. We need investments in skills training, public infrastructure and innovation.

The Liberal government will work with provinces and territories to overcome obstacles to innovation in health care delivery and disseminate and scale up successful new practices, such as ways to use genomics in precision medicine. This includes supporting initiatives that help health care providers collaborate, across Canada, to ensure the most appropriate and effective treatments and practices for their patients. By using the best available evidence, governments can work together to support front-line health providers as they deliver high-quality care to Canadians.

Green: The Green Party supports an arms-length health care innovation fund. Canadian breakthroughs have benefited the world of medicine but funding is decreasing. We will provide robust funding for primary care research. If we are to complete the necessary transition into a patient-centred model, we need to make sure that we are guided by the best possible evidence. This will save money and will help Canadians get the care that they need. The Green Party is committed to allowing scientific evidence to guide policy creation, especially in the area of health. The Harper Conservatives' attacks on medical marijuana and harm reduction are just two examples. Our health care system requires a federal government that understands the implications of the science and funds it properly.

The Canadian Institute for Health Research federal budget has not increased since 2009, meaning that its spending power today has declined by roughly $25 \%$. In addition, CIHR and other funding bodies now favour research with commercial aims. Would your government restore funding and allow institutes to have a broader research focus?

New Democrats: [The Conservative government's] constraints on publicly funded health research and the consequential increased reliance on independently raised corporate funding are fundamentally redefining Canada's research ethos and agenda. By so narrowing our research focus, it potentially robs Canadians of the innovative research initiatives that have yielded landmark successes in the past and redirects this important creative activity elsewhere.

While continuing to encourage the conversion of our health research successes into practical tools to benefit Canadians' well-being, New Democrats share the traditional values that have guided Canada's research inquiry in the past and will, in government, strengthen our research capacity accordingly.

Liberals: We believe that the federal government must continue funding basic research that the private sector focused more on profitability and returns - will not undertake adequately. History shows that such public investment leads to tremendous economic benefits over the longer term, as key discoveries are later adapted for commercial use.

To this end, a Liberal government will invest $\$ 200$ million per year, in each of the next three years, in a new innovation agenda. Working with provinces, postsecondary institutions and industry, this funding will help modernize and strengthen the technology transfer and commercialization functions at universities and colleges. We will also provide direct support to business incubators and accelerators, research facilities, financing and other support for successful small companies wanting to grow and export. The objective is to create successful networks like the American and German partnerships between businesses, gov- ernment and university and college research.

Green: We support properly funding the Canadian Institutes for Health Research to ensure that Canadian ingenuity continues to be a part of our health care system and benefits the world. We oppose the shift of focus to favour research with commercial aims. To access the best available evidence, we need to invest in the best available science. The Green Party believes we must renew our commitment to public science by reinvesting in in our in our federal scientific capacity. We must also defend and promote "discovery science," or basic research. Funding for curiositydriven research is scarce in Canada. Instead of funding scientific inquiry, we are subsidizing the profit-driven research and development of large corporations. The health of basic research in Canada must be restored. We will remove the strings attached to funding that aim towards commercialization and instead direct funding for good science.

If elected, what national commitments will your government bring to the Climate Change Conference in Paris in December 2015 to improve our international climate change performance and to show strong leadership on reducing greenhouse gas emissions?

New Democrats: Our message to Paris delegates is that under a New Democratic government, Canada will:

- rise to meet our international climate change obligations through a transition to a clean economy;

- reduce our reliance on fossil fuels and support energy efficiency and conservation;

- implement a cap-and-trade system that puts a price on carbon;

- kick-start our clean energy sector to make us a global market leader;

- eliminate the billion-dollar subsidies to the fossil fuel industry; and

- restore our international reputation on the environment.

The NDP is the only party to have introduced legislation in the House of Commons that would require the government to develop targets for green- 
house gas emission reductions, and to present a plan to assess progress on meeting the targets and work with provinces and territories, as well as the public and key stakeholders, to achieve those targets. Our current 2025 target is $34 \%$ below 1990 levels, with the longterm target of $80 \%$ by 2050 .

Liberals: As Prime Minister, Justin Trudeau will attend the December 2015 UN Climate Change Conference in Paris and invite all the premiers to join him. Within 90 days of the conference, a First Ministers meeting will be held to work together on a framework to combat climate change. Central to this is the creation of national emissions-reduction targets. These targets must recognize the economic cost and catastrophic impact that a greater-than two-degree increase in average global temperatures would represent, and the necessity for Canada to do its part to prevent that from happening.

We will ensure that the provinces and territories have the tools to design their own policies to meet these commitments, including their own carbon pricing policies. We will provide targeted federal funding to help them achieve these goals.

Any serious plan to reduce carbon emissions requires a federal government that is engaged and committed to partnering with provinces/territories.

Green: We are committed to serious action to avert a climate crisis. Canada needs to put its strongest foot forward in Paris. Our MPs will always work across party lines, because we understand the only way to make progress is through cooperation and mutual respect.

Our plan is to move to the virtual elimination of fossil fuel use in Canada by mid-century. Our short-term target is $40 \%$ below 2005 levels by 2025, while we are calling for $80 \%$ reductions below 1990 levels by 2050. These are ambitious targets, yet the scale and urgency of this challenge demands nothing less. As Canadians, we will rise to this challenge and, in doing so, create a strong, stable, and prosperous economy today and for our children and grandchildren tomorrow. It is absolutely critical that we have a change in government and a strategy when Canada participates in these negotiations in Paris.

Federally employed scientists are not allowed to talk about their research, or, in most cases, speak as expert sources to media. What would your party do to improve transparency in publicly funded science and provide Canadians with improved accessed to scientific expertise within the public service?

New Democrats: A NDP government will actively seek to counter the antiscience reputation of the Harper government that is undermining Canada's ability to attract top-rated scientists. Our scientific community has taken the unprecedented step of holding nationwide public demonstrations to protest the Harper government's direction.

A New Democratic government will move quickly to restore our sciencefriendly reputation in order to retain researchers and attract those working elsewhere on health research and in other fields in order to replenish our scientific community. We need to get Canada's research agenda back on track as quickly as possible.

A NDP government will unmuzzle federally employed scientists and return to evidence-based rather than ideology-based policymaking.

Liberals: Government should base its policies on facts, not make up facts based on policy. Without evidence, government makes arbitrary decisions that have the potential to negatively affect the daily lives of Canadians. Unfortunately, the Conservatives have allowed ideology to trump common sense, good policy and evidence about what works. We will ensure the federal government rebuilds its capacity to deliver on evidence-based decision-making.

We will revoke rules and regulations that muzzle government scientists and allow them to speak freely about their work, with only limited, publicly stated exceptions. We will consolidate government science so that it is easily available to the public at large through a central portal. We will create a Chief Science Officer whose mandate would include ensuring that government science is freely available to the public, that scientists are able to speak freely about their work and that scientific analyses are appropriately considered when the government makes decisions.

Green: Public science belongs to the people. In June 2015, [Green Party Leader] Elizabeth May introduced the Public Access to Science Act to make all publicly funded scientific research publicly accessible by law. As May said at the time, "My bill will ensure that no prime minister can ever bury government science again. While this problem is not new, the Harper years have seen a shocking burial of evidence into places where Canadians will never see it. The work our scientists do is too important to be hidden from view, simply because it is inconvenient to the Prime Minister's agenda. The challenges we face require an open and transparent engagement with the facts."

We need to lift the cloud of darkness recently placed on the federal public service, where scientists have been forbidden from sharing their findings with the public. The challenges we face are existential. We need all the evidence we can muster to design the best possible policies to meet them. - Edited by Barbara Sibbald, CMAJ

CMAJ 2015. DOI:10.1503/cmaj.109-5182 